\title{
Hyponatremia and Inflammation: The Emerging Role of Interleukin-6 in Osmoregulation
}

\author{
Reinout M. Swart Ewout J. Hoorn Michiel G. Betjes Robert Zietse \\ Department of Internal Medicine - Nephrology, Erasmus Medical Center, Rotterdam, The Netherlands
}

\section{Key Words}

Acute phase response $\cdot$ Infectious disease .

Immuno-neuroendocrinology • Lipopolysaccharides •

Vasopressin

\begin{abstract}
Although hyponatremia is a recognized complication of several inflammatory diseases, its pathophysiology in this setting has remained elusive until recently. A growing body of evidence now points to an important role for interleukin- 6 in the non-osmotic release of vasopressin. Here, we review this evidence by exploring the immuno-neuroendocrine pathways connecting interleukin- 6 with vasopressin. The importance of these connections extends to several clinical scenarios of hyponatremia and inflammation, including hospital-acquired hyponatremia, postoperative hyponatremia, exercise-associated hyponatremia, and hyponatremia in the elderly. Besides insights in pathophysiology, the recognition of the propensity for antidiuresis during inflammation is also important with regard to monitoring patients and selecting the appropriate intravenous fluid regimen, for which recommendations are provided.

Copyright $\odot 2010$ S. Karger AG, Basel
\end{abstract}

\section{Introduction}

Hyponatremia is the most common electrolyte disorder in clinical medicine and can be encountered in a variety of diseases [1]. Among these are diseases in which inflammation, with or without infection, plays a central role. Classical examples include pneumonia, tuberculosis, meningitis, encephalitis, and human immunodeficiency virus, but hyponatremia has also been described in severe acute respiratory distress syndrome, malaria and dengue $[2,3]$. We recently illustrated the importance of hyponatremia as a marker of inflammatory disease in a patient in whom the analysis for chronic and unexplained hyponatremia eventually led to the discovery of a chronic infection (aspergillosis secondary to antiviral treatment) [4].

In the majority of these diseases, hyponatremia is believed to be caused by the non-osmotic secretion of vasopressin (antidiuretic hormone). Several non-osmotic stimuli for vasopressin release have been identified, including hypovolemia, pain, nausea, and certain drugs [2]. However, more recently, it is becoming increasingly clear that the so-called 'immuno-neuroendocrine interface' can also directly lead to vasopressin release [5]. Although

Reinout M. Swart, MD

PO Box 2040

NL-3000 CA Rotterdam (The Netherlands)

Tel. +31 624287308

E-Mail reinoutswart@hotmail.com 
the interactions are complex and multifactorial, there is mounting evidence for a key role of the cytokine interleukin- $6[6,7]$. Here, our aim is to review the current evidence for the relationship between inflammation and osmoregulation by providing a brief overview of the involved pathways. Subsequently, we discuss in which hyponatremic disorders these mechanisms are likely to play a role, including hyponatremia during inflammation, but also hospital-acquired hyponatremia, postoperative hyponatremia, exercise-associated hyponatremia, and hyponatremia in the elderly (table 1).

\section{Normal Osmoregulation}

Under normal circumstances, water balance is tightly controlled, and minor changes in serum osmolality will affect the release of vasopressin, the major hormone involved in water homeostasis. Several brain areas are involved in sensing serum osmolality and translating this signal to the release of vasopressin. These areas include the supraoptic and paraventricular nuclei (SON, PVN), the subfornical organ (SFO), and the organum vasculosum of the lamina terminalis (OVLT). Osmosensitive neurons possess mechanosensitive cation channels, including those of the transient receptor potential vanilloid family, that help transduce the signal of increased osmolality (reduced cell stretch) to vasopressin release from the posterior pituitary into the circulation $[8,9]$. In addition, hyperosmolarity induces thirst and the subsequent water intake also helps to lower serum osmolality. Vasopressin docks on its vasopressin-2 receptor in the renal collecting duct and stimulates a cyclic AMP-dependent cascade, that results in the insertion of preformed aquaporin- 2 water channels into the apical plasma membrane [10]. The presence of aquaporin-2 allows for the transcellular movement of water, provided that there is an osmotic gradient. Water exits the principal cells through the constitutively expressed basolateral water channels aquaporin-3 and - 4 [10]. Non-osmotic vasopressin release can be 'appropriate' (i.e., caused by hypovolemia or a low effective arterial blood volume) or 'inappropriate'. Clinically, the ensuing syndrome is called the syndrome of inappropriate antidiuretic hormone secretion (SIADH) [2] . SIADH is characterized by euvolemia and high urine sodium and osmolality in the absence of diuretic use, adrenal, thyroid or pituitary insufficiency, edematous disorders (heart failure, liver cirrhosis, nephrotic syndrome), and renal dysfunction [2].
Table 1. Clinical examples of hyponatremia and inflammation

\begin{tabular}{lll}
\hline Clinical disorder & Evidence & Ref. \\
\hline $\begin{array}{l}\text { Hyponatremia } \\
\text { during infection }\end{array}$ & $\begin{array}{l}\text { Hyponatremia has been reported } \\
\text { in several infections, including } \\
\text { pneumonia, meningitis, and HIV }\end{array}$ & 2 \\
\hline $\begin{array}{l}\text { Hospital-acquired } \\
\text { hyponatremia }\end{array}$ & $\begin{array}{l}\text { Development of hyponatremia } \\
\text { coincided with a rise in CRP }\end{array}$ & 32 \\
\hline $\begin{array}{l}\text { Exercise-associated } \\
\text { hyponatremia }\end{array}$ & $\begin{array}{l}\text { Increased vasopressin and IL-6 } \\
\text { after exercise and trend towards } \\
\text { correlation }\end{array}$ & 7 \\
\hline $\begin{array}{l}\text { Hyponatremia } \\
\text { during ageing }\end{array}$ & $\begin{array}{l}\text { No direct evidence in humans, } \\
\text { but ageing rats produce more va- } \\
\text { sopressin and IL-6 during inflam- } \\
\text { mation }\end{array}$ & \\
\hline $\begin{array}{l}\text { Postoperative } \\
\text { hyponatremia }\end{array}$ & $\begin{array}{l}\text { Plasma vasopressin and IL-6 are } \\
\text { both increased after surgery, but } \\
\text { no studies have measured both }\end{array}$ & \\
\hline
\end{tabular}

\section{Biology of Interleukin-6}

During inflammation, several proinflammatory cytokines are secreted into the systemic circulation to initiate the so-called 'acute phase response', which is part of the innate immune system. The most important proinflammatory cytokines are tumor necrosis factor- $\alpha$ (TNF- $\alpha$ ), interleukin (IL)-1 $\beta$, and IL- 6 [11]. When triggered by endotoxins, these cytokines are secreted by monocytes and macrophages in a cascade-like fashion (fig. 1). TNF- $\alpha$ and IL-1 $\beta$ stimulate their own and each other's secretion, and both promote the release of IL-6. Conversely, IL-6 inhibits the endotoxin-induced secretion of TNF- $\alpha$ and the endotoxin- and TNF- $\alpha$-induced secretion of IL- $1 \beta$, which renders it also an anti-inflammatory cy tokine. Because of this dual action, IL- 6 plays a critical role in the control of the overall inflammatory response. The effects of circulating IL- 6 are mediated through a cell surface heterodimeric receptor complex composed of a ligandbinding subunit, the IL- 6 receptor (IL-6R), and a signaltransducing subunit called gp130 (fig. 2). The binding of IL- 6 to its receptor stimulates the association of the receptor with gp130 and gp130 dimerization [12]. The intracellular signaling pathways downstream from the IL$6 \mathrm{R}$ and the gp130 complex include janus kinases and signal transducers and activators of transcription protein (fig. 2) [13]. The expression of gp130 is ubiquitous while that of IL-6R is restricted to certain cell types. However, 
Fig. 1. Cytokines involved in the inflammatory response. This figure depicts the cascade of events initiated by an inflammatory stimulus. Monocytes and macrophages secrete cytokines in a cascade-like fashion, with TNF- $\alpha$ secreted first, IL-1 $\beta$ second, and IL- 6 last. TNF- $\alpha$ and IL-1 $\beta$ stimulate their own and each other's secretion, and both promote the release of IL- 6 . IL- 6 , on the other hand, inhibits the endotoxin-induced secretion of TNF- $\alpha$ and the endotoxin- and TNF- $\alpha$-induced secretion of IL- $1 \beta$ (arrows indicate stimulatory effects, whereas dashed arrows indicate inhibitory effects).

Fig. 2. IL- 6 signaling. IL- 6 either binds the membrane bound IL-6R or binds the soluble IL-6 receptor (sIL-6R). The complex subsequently binds the membrane-bound gp130 which leads to dimerization of two gp130 molecules. This, in turn, activates intracellular janus kinases (JAK) and the intracellular signal transducers and activators of transcription protein (STAT), which ultimately leads to transcription of target genes.
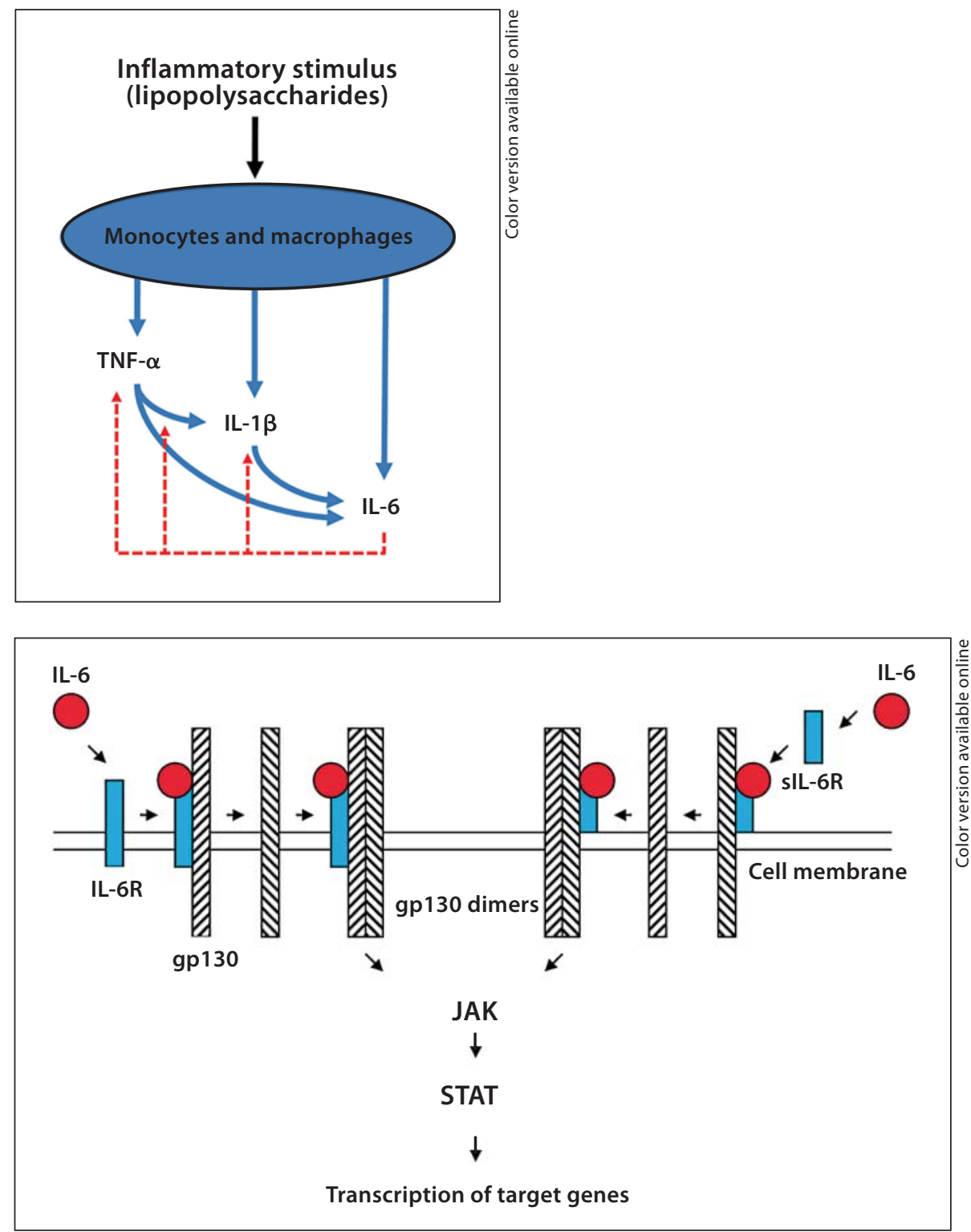

complexes of IL- 6 and soluble IL-6R can elicit responses from gp130-expressing cells that lack cell surface IL-6R, a mechanism known as trans-signaling.

\section{Cytokine-Induced Vasopressin Release}

The most commonly used model to study the immune response has been the intravenous or intraperitoneal injection of lipopolysaccharides (LPS), components of the outer membrane of Gram-negative bacteria. LPS injection induces inflammation and consequently leads to in- creased plasma concentrations of TNF- $\alpha$, IL-1 $\beta$ and IL-6. The observation that LPS, TNF- $\alpha$, IL- $1 \beta$ and IL- 6 can independently or synergistically stimulate the hypothalamus-pituitary-adrenal axis was one of the first pieces of evidence for the existence of immuno-neuroendocrine pathways [14]. Besides the increased secretion of corticotrophin-releasing hormone by the hypothalamus and adrenocorticotropic hormone by the anterior pituitary, increased secretion of the posterior pituitary hormones vasopressin and oxytocin was also observed [15]. LPS-induced vasopressin release was shown to be independent of known stimuli, including serum osmolality, 
Fig. 3. Possible pathways connecting IL-6 to vasopressin release. LPS induce a cascade of cytokine production. LPS and IL$1 \beta$ can induce IL- 6 secretion by the BBB. Circulating IL- 6 can also be transported across the BBB or can simply diffuse across the $\mathrm{BBB}$ in the circumventricular organs. Activation of the subfornical organ and the organum vasculosum of the lamina terminalis by IL-6, nitric oxide (NO), prostaglandins (PG) or LPS, could eventually lead to thirst and increased vasopressin secretion by neurons from the supraoptic nucleus (SON) and paraventricular nucleus (PVN). The combination of antidiuresis and increased water intake may result in hyponatremia.

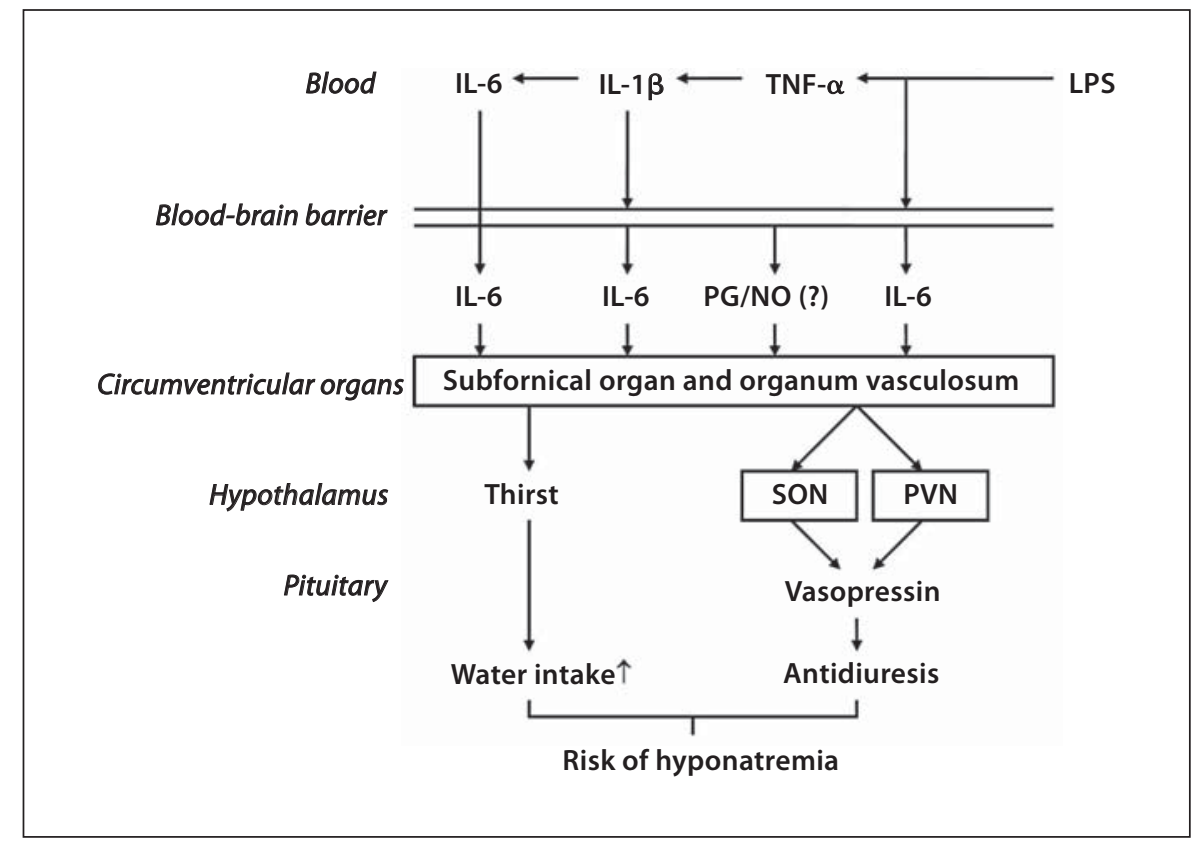

and hemodynamic changes [15]. Interestingly, vasopressin secretion was also stimulated by intravenous injection of IL-1 $\beta$ in rats [16], by intracerebroventricular injection of IL- 6 in rats [17] and, most notably, by intravenous injection of IL-6 in humans [18]. Similarly, oxytocin secretion was stimulated by the administration of LPS or IL-1 $\beta$ [19]. In terms of water balance, the LPS-induced release of oxytocin could be important, because oxytocin has also been shown to have antidiuretic properties, most likely because it can also activate the vasopressin-2 receptor [20].

\section{Interleukin-6 and Vasopressin: Possible Pathways}

Increasing evidence indicates that IL- 6 is a key regulator of vasopressin secretion under physiological conditions. For example, it was recently shown that the expression of vasopressin, oxytocin, and corticotrophin-releasing hormone were decreased in the PVN of IL-6-deficient mice [21]. In addition, the expression of IL-6R co-localized with vasopressin, oxytocin, and corticotrophin-releasing hormone in the PVN and SON. Based on these findings, the authors speculated that IL- 6 could directly stimulate the secretion of these three peptides. In rats, Ghorbel et al. [22] also demonstrated co-localization of IL-6 with vasopressin in the PVN and SON. Furthermore, following dehydration, they showed concurrent upregulation of IL-6 and vasopressin using three inde- pendent techniques, including in situ hybridization, immunochemistry and immunoblotting [22]. Because IL-6 was reduced in the posterior pituitary gland, they speculated that IL- 6 takes the same secretory pathway as vasopressin and is secreted from the posterior pituitary [22]. Palin et al. [23] showed that IL-6, vasopressin, but also insulin-like growth factor I play a role in the increased tendency for antidiuresis during ageing. Namely, during LPS infusion, aged rats exhibited more vassopressinergic neuron activity, which was associated with increased IL- 6 mRNA, but decreased insulin-like growth factor I mRNA [23]. Brain pretreatment with neutralizing anti-IL-6 antibodies or recombinant insulin-like growth factor I reversed LPS-induced antidiuresis [23]. Apart from the changes in renal diluting and concentrating capacity during ageing, these experimental data may provide an additional explanation why the elderly are more prone to developing hyponatremia [24].

Although plasma IL- 6 levels are clearly increased during inflammation, it is unclear if IL- 6 crosses the bloodbrain barrier (BBB) and then evokes a response, or whether LPS crosses the BBB and then increases IL-6 locally in the brain (fig. 3). Saturable transport of IL-6 across the BBB exists [25], and the circumventricular organs, which includes the SFO and OVLT, have vascular beds that do not form a strict BBB. Because the neurons in these brain regions also express the IL-6R, this would be a route via which circulating IL- 6 could directly stimulate central 
vasopressin release. However, there also is compelling evidence that LPS induces a local response of IL- 6 in the brain. Namely, it was shown that endothelial cells, smooth muscle cells and pericytes of the BBB secrete IL- 6 in response to IL-1 $\beta$ and LPS (fig. 3) $[26,27]$. Furthermore, through an unknown mechanism, LPS increases both IL-6 mRNA and protein in astrocytes in the SON [23] and in folliculostellate cells in the pituitary [28]. LPS also strongly upregulated IL-6R mRNA in the SFO, OLVT, and PVN, while vasopressin mRNA expression was only increased in the PVN [29]. Other areas of research, including those on the febrile response, have shown that LPS can evoke a central response from the periphery by stimulating the vagus nerve; this response precedes and is independent of cytokines [30].

In addition to the observational data, two interventional studies further support a connection between inflammation and central vasopressin release. The first study showed that lesions in the SFO and OVLT attenuated vasopressin secretion in response to LPS [31]. The second study showed that brain injection of IL- 6 increased vasopressin neuron activity to the same extent as peripheral LPS, while brain injection of IL- 6 antibodies prevented the LPS-induced activation of vasopressin neurons [17]. Collectively, these data strongly suggest a role for IL-6 as a locally produced second messenger in the signaling pathways activated by LPS, acting as an effector in those brain areas involved in vasopressin release.

\section{Clinical Examples of Hyponatremia and Inflammation}

In one of our own studies, we showed that hospitalacquired hyponatremia was associated with the acute phase response [32]. In this study, 50 patients with hospital-acquired hyponatremia ('cases', defined as a fall in serum sodium $\geq 7 \mathrm{mmol} / \mathrm{l}$ leading to a serum sodium $<136$ $\mathrm{mmol} / \mathrm{l}$ ) were matched for age, sex, and department of admission to 69 controls (stable serum sodium). Interestingly, cases had a rise in C-reactive protein (median from 23 to $146 \mathrm{mg} / \mathrm{l}$ ) during the development of hyponatremia (serum sodium from $141 \pm 2$ to $130 \pm 4 \mathrm{mmol} / \mathrm{l}$ ), whereas C-reactive protein decreased in controls (31-24 mg/l, $\mathrm{p}=0.008$ ). In addition, the use of antibiotics (likely a surrogate marker for infection) was more common among cases ( $82 \mathrm{vs.} 55 \%$ ), and was also an independent predictor for hospital-acquired hyponatremia. Similarly, Ferreira da Cunha et al. [33] showed that hyponatremia was three times more common in postoperative patients with the acute phase response. In both studies, many patients received hypotonic fluids (38 and 55\%, respectively). Thus, the acute phase response likely caused a state of antidiuresis, which resulted in hyponatremia because a source of electrolyte-free water was administered.

The study by Ferreira da Cunha et al. [33] also shows that the acute phase response may play a role in the pathogenesis of postoperative hyponatremia. The non-osmotic release of vasopressin after surgery has clearly been established [34], but the etiology has remained unclear and has mainly been attributed to pain, nausea, anesthetics, and other drugs. However, several studies have shown elevated IL-6 levels after surgery [35]. Interestingly, one of these studies showed a relationship between the levels of IL- 6 and the degree of confusion, but unfortunately serum sodium was not reported [36]. No direct correlation studies between IL-6, vasopressin, and hyponatremia have been performed, but this is clearly an area for future research.

In patients, support for a relationship between IL- 6 and vasopressin release has been shown in a small phase I trial including patients with malignant tumors. Mastorakos et al. [18] showed that in these patients the administration of IL-6 resulted in a fast dose-dependent rise in vasopressin concentration (to $15.6 \mathrm{pg} / \mathrm{ml}$, normal range $\sim 1-4 \mathrm{pg} / \mathrm{ml}$ ). Importantly, IL-6 treatment did not influence TNF- $\alpha$ or IL- $1 \beta$ concentrations, suggesting that vasopressin release by IL- 6 can occur independently of its associated cytokines. Since this study, a number of case reports have reported elevated IL- 6 concentrations during hyponatremia and inflammation. Murakami et al. [37] reported a case of SIADH with increased vasopressin concentrations $(7.2 \mathrm{pg} / \mathrm{ml})$ in a 66-year-old man with inflammatory arthropathy. In this case, IL- 6 concentrations were markedly increased $(96 \mathrm{pg} / \mathrm{ml}$, normal range $<5.0 \mathrm{pg} / \mathrm{ml}$ ), whereas plasma IL- $1 \beta$ and TNF- $\alpha$ concentrations were normal or only mildly increased. In another patient, SIADH was diagnosed in the setting of a urinary tract infection [38]. Both plasma vasopressin $(6.7 \mathrm{pg} / \mathrm{ml})$ and IL-6 $(24.1 \mathrm{pg} / \mathrm{ml})$ were increased at the time of diagnosis of SIADH, and serum sodium and Creactive protein showed an inverse relationship during treatment. Again, TNF- $\alpha$ and IL- $1 \beta$ concentrations remained within the normal range. A more systematic study was performed by Gionis et al. [39] who studied 8 children who had developed an aseptic inflammatory response with SIADH after neurotrauma. In these children, plasma IL-6 concentrations $(20.25 \pm 12.60 \mathrm{pg} / \mathrm{ml})$ were strongly correlated $(\mathrm{r}=+0.96)$ with plasma vasopressin concentrations $(5.42 \pm 2.09 \mathrm{pg} / \mathrm{ml})$, thereby suggesting a role for IL- 6 in the pathogenesis of SIADH. 
Another interesting example of hyponatremia and inflammation is exercise-associated hyponatremia. In the 2002 Boston Marathon, 13\% of the runners included in the study developed hyponatremia, which was associated with weight gain, high fluid intake, female sex, long racing time, and body mass index extremes [40]. Although excessive fluid intake clearly plays a role in the pathogenesis of exercise-associated hyponatremia, it cannot be the only factor. Namely, in the absence of renal insufficiency, kidneys are able to excrete up to almost 1 liter of electrolyte-free water per hour. Indeed, inappropriate antidiuresis has been shown to contribute to exercise-associated hyponatremia [41]. It has been postulated that this antidiuresis could be due to exercise-induced muscle injury leading to a rise in muscle-derived IL-6 [7]. Siegel [7] reported a strong increase in IL- 6 concentrations (from 1.6 \pm 0.5 to $66.6 \pm 11.9 \mathrm{pg} / \mathrm{ml}$ ) in 33 marathon runners, which was significantly correlated with increases in creatine kinase, cortisol, and prolactin. Vasopressin secretion $(2.86 \mathrm{pg} / \mathrm{ml}$ pre-race vs. $4.33 \mathrm{pg} / \mathrm{ml}$ post-race) was considered inappropriate, because hyponatremia was associated with a low blood urea nitrogen. Vasopressin concentrations nearly reached a significant correlation with the observed increase in IL- 6 concentrations $(p=0.07)$ in this small sample group.

\section{Clinical Perspective}

The evolving insight regarding the relationship between IL- 6 and vasopressin is not only an intriguing example of immuno-neuroendocrinology, but it is also relevant for understanding the pathophysiology of hyponatremia during inflammation. Therapeutically, hyponatremia during inflammation is challenging, especially when there is imminent septic shock, because in these circumstances other aspects prevail, including antibiotic therapy, and controlling hemodynamics. However, it is important for physicians to beware of the predisposition to antidiuresis in this context and adjust intravenous fluid therapy accordingly. This implies that hypotonic fluids should be avoided. Importantly, isotonic fluids can also cause hyponatremia, especially when the urine tonicity (sodium plus potassium) exceeds that of the infusate [42]. If clinically relevant hyponatremia is present and hemodynamics are under control, routine therapy for SIADH should be instituted. The usual treatment for SIADH is fluid restriction or hypertonic saline if hyponatremia is symptomatic, although other options such as furosemide, urea, demeclocycline and lithium have been re- ported to be effective in certain cases [2]. If there is a place for the recently approved vasopressin-receptor antagonists also remains to be seen [2]. Successful treatment of transient hyponatremia in hospitalized neurosurgical patients has recently been reported using intravenous conivaptan, a combined vasopressin-1a/2 receptor antagonist [43]. However, acute inflammation is frequently accompanied by vasodilation and hypotension; in these situations, vasopressin-receptor antagonists should be avoided as they may cause extracellular fluid volume contraction and thereby contribute to hypotension. As proof of principle, assessment of the effect of anti-IL- 6 antibodies on the effect of vasopressin release and hyponatremia during inflammation would be of great interest [44].

IL-6 release is just one of the pleiotropic effects of systemic inflammation, and clearly other mechanisms can contribute to vasopressin release and hyponatremia during inflammation, such as hypovolemia or hyperglycemia. In addition, several unanswered questions remain, including the precise neurobiological pathways, why some infections cause hyponatremia more often than others, if vasopressin can also be produced ectopically during infection [45], and the role of the kidney during inflammation [46]. We also acknowledge that there are situations in which IL- 6 is elevated but hyponatremia is rare (e.g. rhabdomyolysis), suggesting that IL-6-mediated vasopressin release is organ-specific or requires additional circulating factors.

In conclusion, there is now convincing data to support a role for IL- 6 in the non-osmotic release of vasopressin and this mechanism may play a role in clinically significant forms of hyponatremia and inflammation.

\section{Disclosure Statement}

All authors declare they have no conflict of interest with regard to this article.

References 
$\checkmark 5$ Melmed S: Series introduction. The immuno-neuroendocrine interface. J Clin Invest 2001;108:1563-1566.

-6 Papanicolaou DA, Wilder RL, Manolagas SC, Chrousos GP: The pathophysiologic roles of interleukin-6 in human disease. Ann Intern Med 1998;128:127-137.

7 Siegel AJ: Exercise-associated hyponatremia: role of cytokines. Am J Med 2006;119:S74S78.

$\checkmark 8$ Bourque CW, Oliet SH: Osmoreceptors in the central nervous system. Annu Rev Physiol 1997;59:601-619.

-9 Sharif-Naeini R, Ciura S, Zhang Z, Bourque CW: Contribution of TRPV channels to osmosensory transduction, thirst, and vasopressin release. Kidney Int 2008;73:811-815.

$>10$ Nielsen S, Frøkiaer J, Marples D, et al: Aquaporins in the kidney: from molecules to medicine. Physiol Rev 2002;82:205-244.

-11 Gabay C, Kushner I: Acute-phase proteins and other systemic responses to inflammation. N Engl J Med 1999;340:448-454.

$\checkmark 12$ Arzt E: gp130 cytokine signaling in the pituitary gland: a paradigm for cytokine-neuroendocrine pathways. J Clin Invest 2001;108: 1729-1733.

-13 Murakami M, Hibi M, Nakagawa N, et al: IL6-induced homodimerization of gp130 and associated activation of a tyrosine kinase. Science 1993;260:1808-1810.

-14 Sapolsky R, Rivier C, Yamamoto G, et al: Interleukin-1 stimulates the secretion of hypothalamic corticotropin-releasing factor. Science 1987;238:522-524.

-15 Kasting NW, Mazurek MF, Martin JB: Endotoxin increases vasopressin release independently of known physiological stimuli. Am J Physiol 1985;248:E420-E424.

-16 Landgraf R, Neumann I, Holsboer F, Pittman QJ: Interleukin-1 $\beta$ stimulates both central and peripheral release of vasopressin and oxytocin in the rat. Eur J Neurosci 1995;7: 592-598.

17 Palin K, Moreau ML, Sauvant J, et al: Interleukin- 6 activates arginine vasopressin neurons in the supraoptic nucleus during immune challenge in rats. Am J Physiol 2009; 296:E1289-E1299.

-18 Mastorakos G, Weber JS, Magiakou MA, et al: Hypothalamic-pituitary-adrenal axis activation and stimulation of systemic vasopressin secretion by recombinant interleukin-6 in humans: potential implications for the syndrome of inappropriate vasopressin secretion. J Clin Endocrinol Metab 1994;79: 934-939.

19 Naito Y, Fukata J, Shindo K, et al: Effects of interleukins on plasma arginine vasopressin and oxytocin levels in conscious, freely moving rats. Biochem Biophys Res Commun 1991;174:1189-1195.
20 Li C, Wang W, Summer SN, et al: Molecular mechanisms of antidiuretic effect of oxytocin. J Am Soc Nephrol 2008;19:225-232.

21 Benrick A, Schéle E, Pinnock SB, et al: Interleukin-6 gene knockout influences energy balance regulating peptides in the hypothalamic paraventricular and supraoptic nuclei. J Neuroendocrinol 2009;21:620-628.

22 Ghorbel MT, Sharman G, Leroux M, et al: Microarray analysis reveals interleukin- 6 as a novel secretory product of the hypothalamo-neurohypophyseal system. J Biol Chem 2003;278:19280-19285.

23 Palin K, Moreau ML, Orcel H, et al: Age-impaired fluid homeostasis depends on the balance of IL-6/IGF-I in the rat supraoptic nuclei. Neurobiol Aging 2009;30:1677-1692.

24 Anpalahan M: Chronic idiopathic hyponatremia in older people due to syndrome of inappropriate antidiuretic hormone secretion possibly related to aging. J Am Geriatr Soc 2001;49:788-792.

25 Banks WA, Kastin AJ, Gutierrez EG: Penetration of interleukin- 6 across the murine blood-brain barrier. Neurosci Lett 1994;179: 53-56.

26 Fabry Z, Fitzsimmons KM, Herlein JA, et al: Production of the cytokines interleukin 1 and 6 by murine brain microvessel endothelium and smooth muscle pericytes. J Neuroimmunol 1993;47:23-34.

27 Reyes TM, Fabry Z, Coe CL: Brain endothelial cell production of a neuroprotective cytokine, interleukin-6, in response to noxious stimuli. Brain Res 1999;851:215-220.

28 Lohrer P, Gloddek J, Nagashima AC, et al: Lipopolysaccharide directly stimulates the intrapituitary interleukin-6 production by folliculostellate cells via specific receptors and the $\mathrm{p} 38 \alpha$ mitogen-activated protein $\mathrm{ki}$ nase/nuclear factor- $\mathrm{kB}$ pathway. Endocrinology 2000;141:4457-4465.

29 Grinevich V, Ma XM, Jirikowski G, et al: Lipopolysaccharide endotoxin potentiates the effect of osmotic stimulation on vasopressin synthesis and secretion in the rat hypothalamus. J Neuroendocrinol 2003;15:141-149.

30 Blatteis CM: The onset of fever: new insights into its mechanism. Prog Brain Res 2007;162: 3-14.

31 De Carvalho Borges B, Carnio EC, Elias LL, et al: Lesion of the anteroventral third ventricle $(\mathrm{AV} 3 \mathrm{~V})$ reduces hypothalamic activation and hypophyseal hormone secretion induced by lipopolysaccharide in rats. Brain Res 2006;1115:83-91.

-32 Beukhof CM, Hoorn EJ, Lindemans J, Zietse R: Novel risk factors for hospital-acquired hyponatraemia: a matched case-control study. Clin Endocrinol (Oxf) 2007;66:367372.

33 Ferreira da Cunha D, Pontes Monteiro J, Modesto dos Santos V, et al: Hyponatremia in acute-phase response syndrome patients in general surgical wards. Am J Nephrol 2000;20:37-41.
34 Chung HM, Kluge R, Schrier RW, Anderson RJ: Postoperative hyponatremia. A prospective study. Arch Intern Med 1986;146:333336.

35 Kato M, Suzuki H, Murakami M, et al: Elevated plasma levels of interleukin-6, interleukin-8, and granulocyte colony-stimulating factor during and after major abdominal surgery. J Clin Anesth 1997;9:293-298.

$\checkmark 36$ Kudoh A, Takase H, Katagai H, Takazawa T: Postoperative interleukin-6 and cortisol concentrations in elderly patients with postoperative confusion. Neuroimmunomodulation 2005;12:60-66.

37 Murakami T, Matoba H, Kuga Y, et al: Hyponatremia in a patient with chronic inflammatory disease. Intern Med 1998;37:792795.

38 Ota K, Kumon Y, Hashimoto K: Unexpected impaired consciousness in RA: a rare complication of SIADH induced by increased IL6. Clin Exp Rheumatol 2004;22:134.

39 Gionis D, Ilias I, Moustaki M, et al: Hypothalamic-pituitary-adrenal axis and interleukin- 6 activity in children with head trauma and syndrome of inappropriate secretion of antidiuretic hormone. J Pediatr Endocrinol Metab 2003;16:49-54.

40 Almond CS, Shin AY, Fortescue EB, et al: Hyponatremia among runners in the Boston Marathon. N Engl J Med 2005;352:15501556

41 Hew-Butler T, Jordaan E, Stuempfle KJ, et al: Osmotic and non-osmotic regulation of arginine vasopressin during prolonged endurance exercise. J Clin Endocrinol Metab 2008; 93:2072-2078.

42 Steele A, Gowrishankar M, Abrahamson S, et al: Postoperative hyponatremia despite near-isotonic saline infusion: a phenomenon of desalination. Ann Intern Med 1997;126: 20-25.

43 Murphy T, Dhar R, Diringer M: Conivaptan bolus dosing for the correction of hyponatremia in the neurointensive care unit. Neurocrit Care 2009;11:14-19.

44 Pallua N, Low JF, von Heimburg D: Pathogenic role of interleukin- 6 in the development of sepsis. II. Significance of anti-interleukin- 6 and anti-soluble interleukin- 6 receptor- $\alpha$ antibodies in a standardized murine contact burn model. Crit Care Med 2003;31:1495-1501

45 Vorherr H, Massry SG, Fallet R, et al: Antidiuretic principle in tuberculous lung tissue of a patient with pulmonary tuberculosis and hyponatremia. Ann Intern Med 1970;72: 383-387.

46 Chassin C, Hornef MW, Bens M, et al: Hormonal control of the renal immune response and antibacterial host defense by arginine vasopressin. J Exp Med 2007;204:2837-2852. 